\title{
Colonic cell proliferation in two different ethnic groups with contrasting incidence of colon cancer: is there a difference in carcinogenesis?
}

\author{
A van't Hof, K Gilissen, R J Cohen, L Taylor, Z Haffajee, A L Thornley, I Segal
}

\begin{abstract}
Most studies on colorectal carcinogenesis suggest a field defect, preceding overt development of cancer. The low incidence of adenomatous polyps in the African population, however, suggests that there may be an alternative route for cancer development. The aim of the study was to discover if the difference in incidence of colorectal cancer in Africans compared with the white population is reflected in a different pattern of cell proliferation. Histological normal mucosa from 30 patients (15 white South African (W), 15 South African Africans (A)) with confirmed colon cancer were examined. Proliferating cells were detected using the Ki-67 antigen. In addition, cell proliferation data were obtained, from 30 age matched controls (15 Africans, 15 white South Africans), without colorectal disease. The African controls were significantly younger (mean (SD) (A: 42 (20), W: $66(13), p<0.05)$ ) than the white controls. The second control group had a significantly higher mean (SD) total labelling index (W: 11 (3), A: 6 (4), p<0.05). In addition the proliferative pattern of the white group without evidence of colorectal cancer showed a comparatively large amount of dividing cells in compartment 2, compared with African controls (mean (SD) (W: 21 (8), A: 9 (8), p<0.05)). Mucosa from Africans with cancer showed a proliferative pattern with the same increased total labelling index (A: 15 (5), W: 16 (6), $p=N S$, phase II proliferative lesion) and an even more pronounced upward expansion (phase I proliferative lesion) compared with white cancer patients. This suggests that the mechanism of colorectal carcinogenesis is similar in Africans and the white population. The lack of clinical evidence of the adenoma-carcinoma sequence, and the incidence of cancer at a comparatively young age in Africans may be explained by the fact that colorectal cancer in this ethnic group behaves more aggressively and that adenomatous polyps are rapidly converted into overt cancer before detection.

(Gut 1995; 36: 691-695)
\end{abstract}

Keywords: colonic cell proliferation, colonic cancer.

The exact mechanism of colorectal carcinogenesis is controversial. Some authors support the adenoma-carcinoma sequence, ${ }^{1-6}$ while others state that 'de novo' development of colorectal cancer is not unusual. ${ }^{7-9}$

It is known that colorectal cancer in Africans is uncommon and that adenomatous polyps are rare. ${ }^{10}$ During a 12 year period (1956-1968), only six adenomatous polyps were reported in a review of surgical specimens in a 2000 bed hospital and no polyps were reported in a series of 1000 necropsy examinations, in which the bowel had been routinely opened and inspected. ${ }^{11}$ In a later study (1969-1978), only six (3\%) adenomatous polyps were found in 205 African patients. It was also found that most cancers were unrelated to polyps. ${ }^{12}$ These findings suggest that in Africans, colorectal cancer may have a different genesis to that of the Westernised population.

Data from cell kinetic parameters can give insight into the mechanism of colorectal carcinogenesis. It was suggested that hyperplastic polyps are not related to the histogenetic process of colorectal cancer, because there was no significant difference in cell proliferation in comparison with normal mucosa. ${ }^{15}$ Deschner et al found that the proliferative pattern in crypts of mice and rats were different. It was suggested that the direction of the shift in the major zone of proliferation is related to the type of lesion present in the colonic mucosa. Downward migration seemed to be related with intramucosal formed cancers, and upward migration with adenomatous polyps. ${ }^{8}$

This study compares the proliferative pattern of histologically normal mucosa from African and white patients, with and without colonic cancer. The aim of the study was to assess if the low incidence of colorectal adenomatous polyps and cancer in Africans is reflected in a different pattern of cell proliferation.

\section{Methods}

\section{SPECIMENS}

Specimens were obtained from 30 patients with confirmed colonic carcinoma, selected from the index files of the department of histopathology at the University of Witwatersrand. Only normal appearing colonic mucosa, obtained from the tumour free resection margins, was examined, and mucosa within a distance of $2 \mathrm{~cm}$ from the tumour was excluded. The surgical specimens were routinely fixed in 
TABLE I Demographic and colonic cell proliferation data of Africans and white patients with colorectal cancer

\begin{tabular}{|c|c|c|}
\hline & Africans & White patients \\
\hline $\begin{array}{l}\text { Number } \\
\text { Age (y) (mean (SD)) (range) } \\
\text { Sex } \\
\text { Distance from tumour (mean (SD)) } \\
\text { Dukes's classification }\end{array}$ & $\begin{array}{l}15 \\
48(18)(27-79) \\
9 M, 6 \mathrm{~F} \\
10(8)(\mathrm{n}=12)\end{array}$ & $\begin{array}{l}15 \\
70(12)(44-86)^{\star} \\
8 \mathrm{M}, 6 \mathrm{~F} \\
12(9)(\mathrm{n}=11) \dagger\end{array}$ \\
\hline$x^{2}$ & $\begin{array}{l}0 \\
5 \\
8 \\
2\end{array}$ & $\begin{array}{l}1 \\
4 \\
9 \\
1\end{array}$ \\
\hline $\begin{array}{l}\text { Differentiation } \\
\text { well } \\
\text { moderate } \\
\text { poor }\end{array}$ & $\begin{array}{l}4 \\
9 \\
2\end{array}$ & $\begin{array}{r}1 \\
12 \\
2\end{array}$ \\
\hline $\begin{array}{l}\text { Location } \\
\text { caecum } \\
\text { ascending } \\
\text { transverse } \\
\text { descending } \\
\text { sigmoid } \\
\text { rectum } \\
\text { unknown }\end{array}$ & $\begin{array}{l}3 \\
- \\
- \\
1 \\
5 \\
4 \\
2\end{array}$ & $\begin{array}{l}2 \\
1 \\
2 \\
- \\
3 \\
2 \\
5\end{array}$ \\
\hline $\begin{array}{l}\text { No of crypts counted/patient (mean (SD)) (range) } \\
\text { Positive no of cells/crypt (mean (SD)) (range) } \\
\text { Labelling index }(\times 100) \text { (mean (SD)) (range) } \\
\text { Labelling index }(\times 100) \text { (mean (SD)) }\end{array}$ & $\begin{array}{r}9(3)(6-15) \\
23(9)(6-42) \\
15(5)(6-25)\end{array}$ & $\begin{array}{l}9(2)(6-12) \\
24(9)(13-39) \dagger \\
16(6)(8-27) \dagger\end{array}$ \\
\hline $\begin{array}{l}\text { compartment } 1 \\
\text { compartment } 2 \\
\text { compartment } 3 \\
\text { compartment } 4+5\end{array}$ & $\begin{array}{l}28(8) \\
29(10) \\
14(8) \\
4(6)\end{array}$ & $\begin{array}{l}34(14) \dagger \\
31(12) \dagger \\
13(6) \dagger \\
2(2) \ddagger\end{array}$ \\
\hline
\end{tabular}

${ }^{\star} \mathrm{p}<0.05 ; \mathrm{tp}=\mathrm{NS}$ (analysis of variance); $\neq \mathrm{p}=\mathrm{NS}$ (Mann-Whitney).

formalin and processed. Sections of 4 microns were cut and dried overnight to ensure adequate adhesion before staining.

In addition, biopsy specimens were obtained from 30 age matched control patients (15 Africans, 15 white patients), without colorectal disease. All patients underwent endoscopy between 900 am and $200 \mathrm{pm}$, after whole gut irrigation. Patients signed an informed consent form before the procedure. Biopsy specimens were taken at a mean of $20 \mathrm{~cm}$ (Africans) and of $26 \mathrm{~cm}$ (white patients) from the anal ring. Immediately after the biopsy, the specimens were coded and orientated mucosal side up on filter paper and formalin fixed. Four micro thick sections were cut from paraffin wax blocks. Patients with histologically abnormal mucosa were excluded.

IMMUNOHISTOCHEMISTRY

Proliferating cells were detected, using the MIB1 antibody (DIANOVA GmbH). The MIB1 antibody reacts with the $\mathrm{Ki}-67$ nuclear antigen and has the advantage that it can be used in routinely processed, formalin fixed, paraffin wax sections. ${ }^{13}$

Sections were dewaxed, hydrated, and trypsinised $(0.1 \%$ trypsin) for 15 minutes at $37^{\circ} \mathrm{C}$. While in a citrate buffer $(\mathrm{pH} 6.0)$, slides were exposed to microwave irradiation for a period of nine minutes (three times three minutes). Endogenous peroxidase was blocked, using $0 \cdot 3 \% \mathrm{H}_{2} \mathrm{O}_{2}$ in methanol, for 20 minutes. After washing in phosphate buffered saline the sections were covered with normal horse serum for 20 minutes. The slides were then incubated in the primary antibody (MIB1, dilution 1:10) for 60 minutes at $37^{\circ} \mathrm{C}$. Antibody detection was made with an avidinbiotin horseradish peroxidase complex (VECTASTAIN, ABC) with diaminobenzidine as the chromogen. The sections were lightly counterstained with haematoxylin.

\section{QUANTIFICATION}

Only whole length, longitudinal crypts were selected. These were defined as crypts with the muscularis mucosa at the bottom and the surface at the top. Scoring of nuclei was done manually, by only one observer, with the use of a light microscope $(\times 400)$. Nuclei were counted as positive if any nuclear staining was present.

\section{ANALYSIS}

The parameters used were: the mean number of labelled nuclei per crypt, the mean number of total nuclei per crypt, and the labelling index, which is the ratio of labelled (MIB1 positive) to the total (MIB1 positive + MIB1 negative) number of nuclei. In addition, the crypt was divided into five equally sized compartments (from base to surface) and the number of (labelled) nuclei in each compartment was calculated. This permitted the calculation of a labelling index for each of the five compartments.

\section{Statistical analysis}

One way analysis of variance was used for comparison of the mean values of labelling indices. When data were not normally distributed, the Mann-Whitney test was used.

\section{Results}

PATIENTS WITH COLORECTAL CANCER

Thirty patients (15 South African Africans, 15 South African whites), were selected. The African group was significantly younger. In the Africans four patients had well differentiated tumours compared with one in the white group. For seven patients the exact distance of the mucosa to the tumour was not known (Table I).

\section{PATIENTS WITHOUT COLORECTAL DISEASE}

There was no statistical significant difference in age between patients with colorectal cancer and controls from the same ethnic group. The indications for endoscopy included microcystic anaemia, abdominal pain, diarrhoea, and perirectal bleeding. In one white patient, we found evidence of angiodysplasia and four other patients (two Africans, two white patients) had diverticula. On histological examination one African patient had melanosis coli and another showed an ovum of schistosoma in the section. These abnormalities were thought not to influence the cell proliferation data (Table II).

\section{QUANTITATIVE RESULTS}

\section{Patients with colon cancer}

The total number of labelled nuclei and the total labelling index do not differ significantly between the two ethnic groups. Although there is a trend towards a higher mean labelling 
TABLE II Demographic and colonic cell proliferation data of Africans and white patients without colorectal cancer

\begin{tabular}{|c|c|c|}
\hline & Africans & White patients \\
\hline Number & 15 & 15 \\
\hline Age (y) (mean (SD)) (range) & $42(20)(16-75)$ & $66(13)(30-82)^{\star}$ \\
\hline Sex & $7 \mathrm{M}, 8 \mathrm{~F}$ & $4 \mathrm{M}, 11 \mathrm{~F}$ \\
\hline \multicolumn{3}{|l|}{ Indication for endoscopy } \\
\hline anaemia & 8 & 2 \\
\hline abdominal pain & 1 & 7 \\
\hline constipation & 0 & 1 \\
\hline diarrhoea & 1 & 3 \\
\hline loss of weight & 1 & 0 \\
\hline perirectal bleeding & 4 & 1 \\
\hline unknown & 0 & 1 \\
\hline \multicolumn{3}{|l|}{ Macroscopic pathology } \\
\hline none & 13 & 12 \\
\hline angiodysplasia & 0 & 1 \\
\hline diverticula & 2 & 2 \\
\hline \multicolumn{3}{|l|}{ Microscopic pathology } \\
\hline none & 13 & 15 \\
\hline melanosis coli & 1 & 0 \\
\hline schistosomiasis & 1 & 0 \\
\hline Time of biopsy & $1015-1300$ & $0855-1415$ \\
\hline Distance from anal ring (cm) (mean (SD)) & $20(6)$ & $26(4) \dagger$ \\
\hline No of crypts counted/patient (mean (SD)) (range) & $9(3)(5-15)$ & $9(3)(5-15)$ \\
\hline Positive no of cells/crypt (mean (SD)) (range) & $7(6)(3-25)$ & $13(4)(8-18)^{\star}$ \\
\hline Labelling index $(\times 100)$ (mean $($ SD) $)$ (range) & $6(4)(2-18)$ & $11(3)(7-17)^{\star}$ \\
\hline \multicolumn{3}{|l|}{ Labelling index $(\times 100)$ (mean (SD) } \\
\hline compartment 1 & $15(7)$ & $23(6)^{\star}$ \\
\hline compartment 2 & $9(8)$ & $21(8)^{\star}$ \\
\hline compartment 3 & $4(6)$ & $11(6)^{\star}$ \\
\hline compartment $4+5$ & $0(1)$ & $1(1) \ddagger$ \\
\hline
\end{tabular}

${ }^{\star} \mathrm{p}<0.05 ; \mathrm{tp}=\mathrm{NS}$ (analysis of variance); $\neq \mathrm{p}=\mathrm{NS}$ (Mann-Whitney).

index of the upper crypt compartments in the mucosa from Africans, it is not statistically significant (Table I, Fig 1).

In a subgroup of 23 patients ( 12 Africans, 11 white patients) in which the distance of the mucosa to the tumour was known, the total labelling index of mucosa within a distance of 5 $\mathrm{cm}$ from the tumour, was $19(+5)$ for the African patients and $27(+2)$ for the white patients. Labelling indices from mucosa located more than $5 \mathrm{~cm}$ away from the carcinoma was $12(+4)$ and $15(+4)$ respectively, which is significantly lower $(p<0.05)$ (Table III). This finding is in agreement with previous studies, which report a negative correlation between the distance from the tumour and the cell proliferation rate. ${ }^{914}$

Patients without colorectal disease

Table II summarises epithelial cell proliferation variables for patients without colorectal cancer. The white patients had a significantly

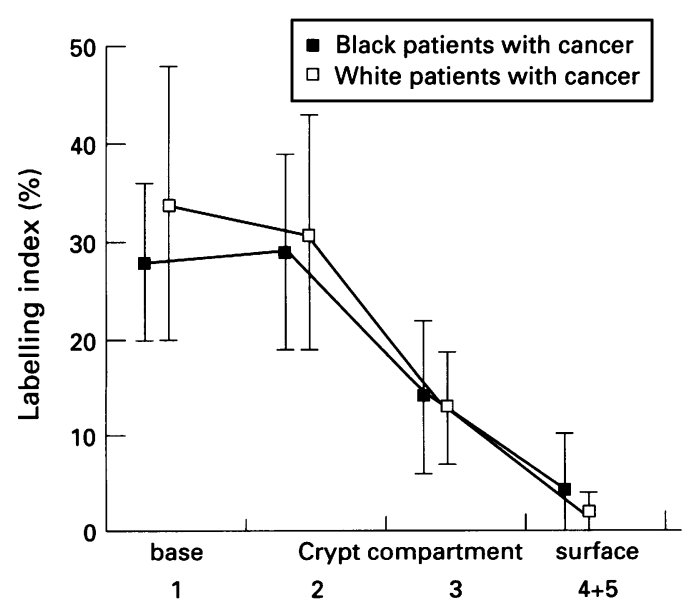

Figure 1: Comparison of labelling index (mean (SD)) in each crypt compartment between the two ethnic groups with colon cancer (compartment 1 is located at the base of the crypt, compartment 5 at the surface). higher mean total labelling index than Africans (phase II proliferative lesion). In addition, the proliferative pattern of white patients without evidence of colorectal cancer, showed a comparatively large amount of dividing cells in compartment 2, compared with the African controls (phase 1 proliferative lesion) (Fig 2). This is in agreement with the results from other studies. ${ }^{15-17}$ They also showed that patients at increased risk of colon cancer may show a proliferative pattern of the mucosa, which is characterised by phase I and phase II proliferative lesions, in the absence of any colorectal abnormality.

\section{Discussion}

The results show that white controls had a significantly higher mean total labelling index than African controls. In addition the proliferative pattern of white controls without evidence of colorectal cancer showed a comparatively large amount of dividing cells in compartment 2, compared with African controls. There was a significant difference in age between white and African controls. Our calculations (Table IV) show, however, that, although there is a trend toward a higher rate of cell proliferation with age, it is not statistically significant.

Much information about colorectal carcinogenesis comes from studies concerning cell proliferation. In 1973, Lipkin described phase I and phase II proliferative lesions in the mucosa from patients at increased risk of colorectal cancer. ${ }^{3} \mathrm{He}$ suggested that neoplastic lesions develop in stages: the adenoma-carcinoma sequence. In support of this hypothesis, clinical and histopathological data indeed have shown that most, if not all, malignant colorectal carcinomas arise from pre-existing adenomas. ${ }^{2}$ These studies mainly concern the Westernised populations. In this group, colorectal cancer is the second most common cancer. In this study, cell proliferation data were obtained from a group of South African Africans, in which colorectal cancer is one of the lowest in the world. Moreover, macroscopic adenomatous polyps are seldom seen. This led to the hypothesis that the adenomacarcinoma sequence does not occur in this ethnic groups. ${ }^{12}$ It was suggested that cancer could have arisen de novo or from flat mucosal lesions in apparently normal mucosa. Little is known about the changes in cell proliferation that occur in de novo carcinogenesis or in carcinomas that arise from flat adenomas. Animal studies suggest that the direction of the shift in the major zone of proliferation is related to the type of lesion: downward migration seemed to be related with intramucosal formed cancers, and upward migration with adenomatous polyps. ${ }^{8}$ In humans, however, a

TABLE III Influence of distance from tumour on rate of epithelial cell proliferation

\begin{tabular}{lll}
\hline Distance from tumour & $<5 \mathrm{~cm}$ & $>5 \mathrm{~cm}$ \\
\hline Labelling index black patients & $19(5)$ & $12(4)^{\star}$ \\
Labelling index white patients & $27(2)$ & $15(4)^{\star}$ \\
\hline
\end{tabular}

${ }^{\star} \mathrm{p}<0 \cdot 05$. Data shown as mean $(\mathrm{SD})$. 


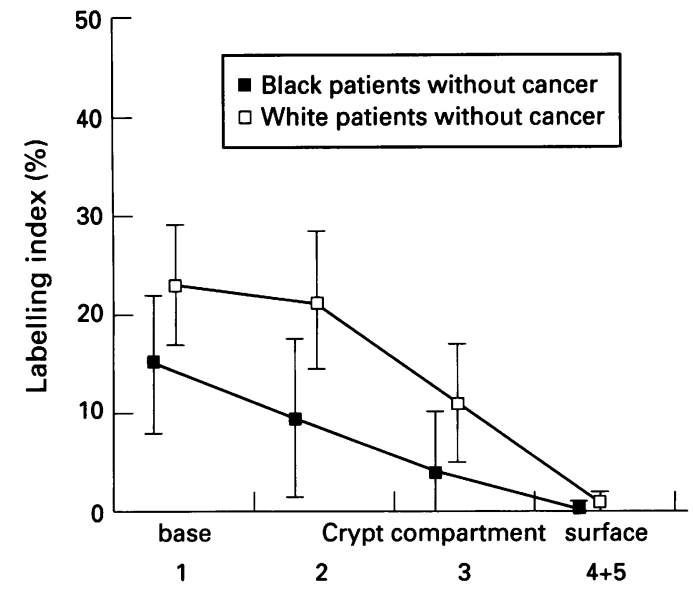

Figure 2: Comparison of labelling index (mean (SD)) in each crypt compartment between the two ethnic groups without colon cancer (compartment 1 is located at the base of the crypt, compartment 5 at the surface).

downward shift would not be evident as such, as the major zone of cell proliferation is already located at the base of the crypt. ${ }^{18}$ Thus, a pattern of cell proliferation would be expected to be found in mucosa from Africans with colon cancer, in which no significant changes in mucosal cell proliferation is present. In this study, however, the mucosa from Africans with colorectal cancer showed an even more pronounced upward shift of the proliferating cells (phase I proliferative lesion) compared with the changes in proliferative pattern, which occur in mucosa from South African white patients with cancer (Fig 3). This suggests that colorectal cancer in Africans is also preceded by adenomas. We reviewed all slides in an attempt to find more evidence of the adenomacarcinoma sequence in Africans. In two tumours from African patients, it was obvious that the tumour arose from a tubulovillous adenoma. Another African patient had a tubulovillous polyp with severe dysplasia located proximal from the tumour. The white group showed the same percentage of tumours (two of 15, 13\%), in which the originating polyp could be found.

If the adenoma-carcinoma sequence were a common event, however, it might be expected that adenomatous polyps would be more common in African patients. This does not seem to occur. ${ }^{12} \mathrm{~A}$ possible mechanism to consider is that colonic cancer may behave more aggressively in this ethnic group. In this

TABLE IV Influence of age on epithelial cell proliferation in patients without colorectal disease

\begin{tabular}{lcc}
\hline & Young $(<67)$ & Old $(\geqslant 67)$ \\
\hline Africans (n) & 11 & 4 \\
Total labelling index (LI) & $5 \cdot 3(3 \cdot 3)$ & $8 \cdot 3(6 \cdot 7)^{\star}$ \\
( $\times 100)$ & $13 \cdot 7(6 \cdot 5)$ & $17 \cdot 8(8 \cdot 2)^{\star}$ \\
LI compartment 1 & $7 \cdot 5(5 \cdot 6)$ & $14 \cdot 8(12 \cdot 7)^{\star}$ \\
LI compartment 2 & $2 \cdot 8(3 \cdot 9)$ & $7 \cdot 3(9 \cdot 2)^{\star}$ \\
LI compartment 3 & $0 \cdot 3(0 \cdot 5)$ & $0 \cdot 5(1 \cdot 0)^{\star}$ \\
LI compartment 4+5 & 6 & 9 \\
White patients (n) & & \\
Total labelling index (LI) & $11 \cdot 3(2 \cdot 3)$ & $11 \cdot 0(4 \cdot 0)^{\star}$ \\
( $\times 100)$ & $24 \cdot 8(6 \cdot 2)$ & $21 \cdot 6(5 \cdot 5)^{\star}$ \\
LI compartment 1 & $20 \cdot 3(5 \cdot 0)$ & $21 \cdot 1(9 \cdot 2)^{\star}$ \\
LI compartment 2 & $9 \cdot 2(4 \cdot 5)$ & $11 \cdot 7(6 \cdot 6)^{\star}$ \\
LI compartment 3 & $1 \cdot 0(0 \cdot 9)$ & $0 \cdot 9(0 \cdot 8)^{\star}$ \\
LI compartment 4+5 & &
\end{tabular}

${ }^{\star} \mathrm{p}=\mathrm{NS}$. Data shown as mean (SD). way, a single precursor lesion, which may only be $1-2 \mathrm{~mm}$ in size, may be rapidly replaced by overt cancer, before being detected. In this study it was found that mucosa from Africans with colon cancer showed a more pronounced phase I and phase II proliferative lesions despite a significantly younger age. We suggest that the mucosal changes in Africans progress from a very low risk pattern (as seen in controls) to a high risk pattern in a comparatively short period of time, consistent with a more aggressive tumour behaviour than occurs in white patients. Also other authors suggest a different, possibly more aggressive tumour behaviour in Africans. Michelassi et al found different karyotypic characteristics of the neoplastic cells in tumours from Africans. ${ }^{19}$ Dayal found that the African race was an independent risk factor, associated with a poor survival from colorectal cancer. ${ }^{20}$ This study suggests that there are at least two varieties of the adenoma-carcinoma sequence: one in which clearly visible adenomas are gradually replaced by malignant tumour (the most likely mechanism in white patients), and one in which a less easy detectable precursor lesion (?flat adenoma) is rapidly replaced by overt cancer (proposed mechanism in Africans). It is suggested that de novo carcinogenesis is a variant of the adenoma-carcinoma sequence. This model is consistent with the hypothesis of Hill et $a l^{21}$ and Fearon and Vogelstein, ${ }^{2}$ who describe a stepwise model for colorectal
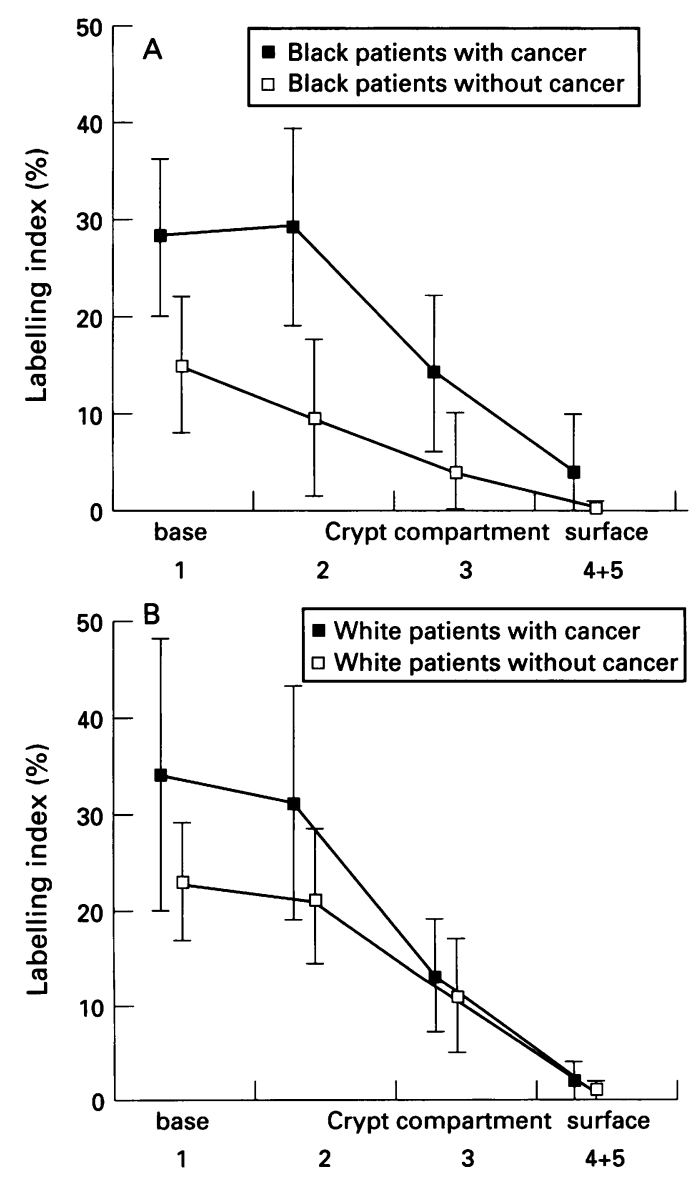

Figure 3: Proliferation pattern of $(A)$ Africans and (B) white patients with colon cancer, compared with controls without colorectal disease. Note the more pronounced phase I and phase II proliferative lesions in the mucosa from Africans with cancer. 
tumorigenesis. Intervention at various stages of tumour development, either by (in)activation of certain oncogenes or suppressorgenes, ${ }^{2}$ or by the absence or presence of environmental factor $A, B$, or $C, 21$ could explain which variety of adenoma-carcinoma sequence occurs. Studies evaluating the genetic basis of colorectal cancer in low risk communities may uncover important data and assist in elucidating clues to colorectal cancer pathogenesis.

1 Risio M, Coverlizza S, Ferrari A, Candelaresi GL, Rossini FP. Immunohistochemical study of epithelial cell proliferation in hyperplastic polyps, adenomas and adenocarcinomas of the large bowel. Gastroenterology 1988; 94: 899-906.

2 Fearon ER, Vogelstein B. A genetic model for colorectal tumorigenesis. Cell 1990; 61: 759-67.

3 Lipkin M. Phase 1 and phase 2 proliferative lesions of colonic epithelial cells in diseases leading to colonic cancer. Cancer 1974; 34 (suppl): 878-88.

4 Lane $\mathrm{N}$. The precursor tissue of ordinary large bowel cancer. Cancer Res 1976; 86: 2669-72.

5 O'Brien MJ, O'Keane JC, Zauber A, Gottlieb LS, Winawer SJ. Precursors of colorectal carcinoma, biopsy and biologic markers. Cancer 1992; 70 (suppl): 1317-27.

6 Hamilton SR. The adenoma-adenocarcinoma sequence in the large bowel: variations on a theme. $\mathcal{F}$ Cell Biochem 1992; 16G (suppl): 41-6.

7 Maskens AP, Dujardin-Loits RM. Experimental adenomas and carcinomas of the large intestine behave as distinct and carcinomas of the large intestine behave as distinct entities: most carcinom

8 Deschner EE, Maskens AP. Significance of the labelling index and labelling distribution as kinetic parameters in colorectal mucosa of cancer patients and DMH treated animals. Cancer 1982; 50: 1136-41.
9 Shamsuddin AKM, Weiss L, Phelps PC, Trump BF. Colon epithelium IV: human colon carcinogenesis. Change in human colon mucosa adjacent to and remote from carcinomas of the colon. $\mathcal{F}$ Natl Cancer Inst 1981; 66: 413-9.

10 Burkitt DP. Epidemiology of cancer of the colon and rectum. Cancer 1971; 28: 3-13.

11 Bremner CG, Ackerman LV. Polyps and carcinoma of the large bowel in the South African Bantu. Cancer 1970; 26: 991-9.

12 Segal I, Cooke SAR, Hamilton DG, Ou Tim L. Polyps and colorectal cancer in South African Africans. Gut 1981; 22: 653-7.

13 Key G, Becker MHG, Duchrow M, Schluter C, Gerdes J New $\mathrm{Ki}-67$ equivalent murine monoclonal antibodies (MIB1-3) generated against recombinant parts of the Ki67 antigen. Anal Cell Pathol 1992; 4: 181.

14 Kyzer S, Mitmaker B, Gordon PH, Schipper H, Wang E. Proliferative activity of colonic mucosa at different distances from primary adenocarcinoma as determined by the presence of statin: a non-proliferation-specific nuclear protein. Dis Colon Rectum 1992; 35: 879-83.

15 Roncucci L, Ponz de Leon M, Scalmati A, Pratissoli S, Perini M, Chahin NJ. The influence of age on colonic Perini M, Chahin NJ. The influence of age on colon
epithelial cell proliferation. Cancer 1988; 62: 2373-7.

16 Deschner EE, Godbold J, Lynch HT. Rectal epithelial cell proliferation in a group of young adults. Influence of age and genetic risk for colon cancer. Cancer 1988; 61 2286-90.

17 Rozen P, Fireman Z, Fine N, Chetrit A, Lubin F. Recta epithelial proliferation of first degree relatives of sporadic colon cancer patients. Cancer Lett 1990; 51: 127-32.

18 Risio M. Cell proliferation in colorectal tumor progression an immunohistochemical approach to intermediate biomarkers. $₹$ Cell Biochem 1992; 16G (suppl): 79-87.

19 Michelassi F, Vannucci LE, Montag AG, Dytch HE, Bibbo $M$. Nuclear morphometric measurements in rectal adenoM. Nuclear morphometric measurements in rectal adeno-
carcinoma cells of patients of different races. Anal Quant carcinoma cells of patients of

20 Dayal H, Polissar L, Yang CY, Dahlberg S. Race, socioeconomic status, and other prognostic factors for survival from colo-rectal cancer. $f$ Chron Dis 1987; 40: 857-64. 21 Hill MJ, Morson BC, Bussey HJR. Aetiology of adenomacarcinoma sequence in large bowel. Lancet 1978; i: 245-7. 
key topics' category. It should be judged in these terms, of course, as it is not a textbook of paediatric gastroenterology. The authors of the chapters are well recognised names in the community of paediatric gastroenterologists, from North America and from the United Kingdom, with one representative from continental Europe. Predictably, all have undertaken their task competently and successfully.

The success of the publication must depend on the choice of topics included. This is good in the main, but at times somewhat specialist. The generalist who sees children with gastrointestinal problems will find the chapters on oral rehydration solution, constipation, food allergy, inflammatory bowe disease, gastro-oesophageal reflux, recurrent abdominal pain, and gastrointestinal bleeding, of great interest and educational value. The chapter on 'when to transplant the liver in children' fits uncomfortably; it is a very interesting question for the paediatric hepatologist or specialist gastroenterologist but of little relevance to the probable readership of the publication. The chapters on the role of gastrointestinal motility studies and of home parenteral nutrition fall in between, probably The relevance of the book to a reader wil depend on the number of children with these problems they see, and I suspect that the book will be most useful to the general paediatrician and not the general gastroenterologist

In keeping with the ethos of counting credits, I would rate this book as being worth three credits (assuming that most generalists would probably read six chapters, and perhaps spend half an hour on each). By doing this, they are probably learning more than by earning six credits by listening to the same authors giving lectures on the same topics, and in addition they have the book on their shelves afterwards. Paediatricians should put it on their reading list for next term, as should any general gastroenterologist who sees children.

S P DEVANE

\section{NOTES}

\section{Wilson's disease and Menkes' disease}

The 7th International Symposium on Wilson's disease and Menkes' disease will be held in Vienna, Austria on 25-27 August 1995. Further information from: Prof Dr Peter Ferenci, Department of International Medicine IV, Gastroenterology and Hepatology, Währinger Gürtel 18-20, A-1090 Vienna, Austria. Tel: (43 1) 404004741 ; fax: (43 1) 4040047350

\section{Neurogastroenterology}

An International Symposium on Neurogastroenterology will be held on 10-11 November 1995 in Rome, Italy. Further information from: Dr Enrico Corazziari, Cattedra di Gastroenterologia I, Clinica
Medica II, Policlinico Umberto I, V le del Policlinico, 00161, Rome, Italy. Tel/fax: 39 6-4469965

\section{Paediatric gastroenterology}

The 1st International Congress of Pediatric Gastroenterology will be held in Jaipur, India on 12-16 December 1995. Further information from: Dr Balvir S Tomar, Head, Department of Pediatric Gastroenterology, 4 Govind Marg, Jaipur, 302 004, India. Tel: 91141604040 or 605050 ; fax: 91141 563788

\section{Gastroenterology}

A Postgraduate Gastroenterology Course will be held in Oxford on 7-10 January 1996 Further information from: Dr D P Jewell, Gastroenterology Unit, Radcliffe Infirmary, Woodstock Road, Oxford OX2 6HE. Tel: 01865 224829; fax: 01865790792

\section{Inflammatory bowel disease}

The International Inflammatory Bowel Disease Symposium will be held in Chester on 14-16 April 1996. Further information from: Prof Jonathan M Rhodes, Department of Medicine, Liverpool University, L69 3BX. Tel: 0151706 3558; fax: 01517065802.

ABIM announcement regarding change in training requirements for certification in gastroenterology

The American Board of Internal Medicine announces a new policy requiring three years of accredited training in a gastroenterology fellowship programme.

This decision follows a lengthy review by the ABIM Subspecialty Board on Gastroenterology and has the support of the American Gastroenterological Association, the American College of Gastroenterology, the American Society of Gastrointestinal Endoscopy, the American Association for the Study of Liver Diseases, and the Gastroenterology Training Program Directors.

This new policy becomes effective for fellows entering gastroenterology fellowship training programmes in June 1996 and thereafter. Trainees who have questions about this policy should contact the American Board of Internal Medicine, 3624 Market Street, Philadelphia, Pennsylvania, 19104-2675, USA.

\section{Falk Symposia}

Details of Falk Symposia for 1995 and 1996 and the Basel Liver Week 1995 are now available. Further information from: Falk Foundatione V, Leinenweberstraße 5, Postfach 65 29, D-79041 Freiburg, Germany. Fax: 0761/13034-59.

\section{Sir Francis Avery Jones BSG Research Award 1996}

Applications are invited by the Education
Committee of the British Society of Gastroenterology who will recommend to Council the recipient of the 1996 Award. Applications (eighteen copies) should include:

(1) A manuscript (2 A4 pages only) describing the work conducted.

(2) A bibliography of relevant personal publications.

(3) An outline of the proposed content of the lecture, including title.

(4) A written statement confirming that all or a substantial part of the work has been personally conducted in the UK or Eire.

Entrants must be 40 years or less on 31 December 1996 but need not be a member of the BSG. The recipient will be required to deliver a 40 minute lecture at the Spring meeting of the Society in 1996. Applications (eighteen copies) should be made to: The Honorary Secretary, BSG, 3 St Andrews Place, London NW1 4LB by 1 December 1995.

\section{CORRECTIONS}

The authors (Van't Hof et al Gut 1995; 36: 691-5) omitted an acknowledgement from their paper and would like to gratefully acknowledge the support of the Medical Research Council, South Africa.

An authors' error occurred in the paper by Khulusi et al (Gut 1995; 36: 193-7). The second sentence under Clinical Methods should read 'One duodenal biopsy was obtained from the ulcer margin and two from the anterior duodenum', and on the same point the second paragraph of the Discussion should re-affirm that the three duodenal bulb biopsy specimens included 'two from the anterior wall'

Some editorial errors occurred in the paper by Mothes et al (Gut 1995; 36: 548-52). The tenth line of the Methods section should read 'was stopped by the addition of $10 \mathrm{~m}$ acetic acid' and not $100 \mathrm{ml}$. In the legend to Fig 1: lane 2 should read 'gliadin (gli)' and not 'purified gliadin', lane 3 should read 'tryptic digested gliadin (t-gli)' and not 'gliadin'. The abscissa to Fig 3 should begin with zero and not 1 . The legend to Fig 4 should read 'MHC expression by HT-29 cells - influence of gliadin (gli) ( $\bullet$ ), tryptic digested gliadin (t-gli) $(0)$, casein $(\boldsymbol{\nabla})$, tryptic digested casein $(\nabla)$, and $\beta$ lactoglobulin $(\boldsymbol{\square})$ Culture in the presence of interferon $\gamma$ without addition of food derived peptides was $100 \%$. Means of three or four ( $t$-gli, four to seven) individual cultures are shown (^only two cultures performed). For sake of clarity the SEM is given in only one direction'.

Also, 'trypsin' and 'tryptic digestion' has been printed as 'tryptin' and tryptin digestion' throughout the text. 